\title{
Oxycenus maxwelli (Keifer) (Acari: Eriophyidae) danificando a cultura da oliveira, Olea europaea L., no Estado do Rio Grande do Sul
}

\author{
Oxycenus maxwelli (Keifer) (Acari: Eriophyidae) damaging olive tree, Olea europaea L., in Rio Grande \\ do Sul State
}

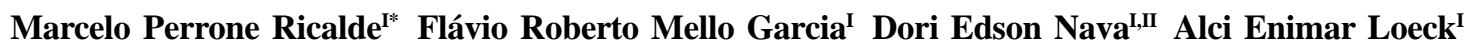 \\ Michele Guimarães Donatti-Ricalde ${ }^{\mathrm{I}}$ Enilton Fick Coutinho $^{\text {II }}$
}

\begin{abstract}
O micro ácaro da oliveira Oxicenus maxwelli RESUMO (Keifer, 1939) foi identificado em pomares de oliveira nos municípios de Santana do Livramento, Bagé, Candiota, Pelotas e Rio Grande, RS, nos meses de novembro de 2010 a fevereiro de 2011. A espécie foi encontrada nas faces superior e inferior de folhas jovens, em flores e brotos, onde causa deformações, queda de folhas e flores, diminuição da fotossíntese e superbrotação, prejudicando a produção da planta e a comercialização dos frutos deformados. Este é o primeiro registro da espécie atacando a oliveira no Estado do Rio Grande do Sul.
\end{abstract}

Palavras-chave: micro-ácaro da oliveira, eriofídeo, praga da oliveira.

\section{ABSTRACT}

The olive bud mite Oxicenus maxwelli (Keifer 1939) was identified in olive groves in the municipalities of Santana do Livramento, Bagé, Candiota, Pelotas and Rio Grande, RS in November 2010 to February 2011. The specie was found on the upper surface and under surface of young leaves, flowers and buds where it causes deformities, loss of leaves and flowers, decreased photosynthesis and budding, damaging the plant's production and marketing of deformed fruits. This is the first record of the species attacking the olive tree in the state of Rio Grande do Sul.

Key words: Olive bud mite, eriophyid, olive pest.

No Brasil, a oliveira foi introduzida há vários séculos, porém com maior frequência nas regiões Sul e
Sudeste (Minas Gerias, Rio de Janeiro, São Paulo, Paraná, Santa Catarina e Rio Grande do Sul). Atualmente, existem áreas com plantios comerciais nos Estados do Rio Grande do Sul (Bagé, Cachoeira do Sul, Caçapava do Sul, Dom Pedrito, Encruzilhada do Sul, Rio Grande, Santana do Livramento e Vacaria), Minas Gerais (Maria da Fé) e em Santa Catarina. A área cultivada é de aproximadamente 400 hectares no RS, apresentando excelentes perspectivas de avanço no cultivo. O Brasil é o quinto maior importador mundial de azeite de oliva e o quarto maior importador mundial de azeitonas de mesa (COUTINHO et al. 2009). Devido ao cultivo comercial ser recente no País, além de ser realizado em pequenas áreas, poucas informações estão disponíveis sobre o manejo da cultura, principalmente em relação aos problemas fitossanitários.

O micro ácaro da oliveira Oxycenus maxwelli (Acari: Eriophyidae) foi descrito na Califórnia (KEIFER, 1939), mas provavelmente sua origem é a região do mediterrâneo, sendo encontrado na Itália, Grécia, Portugal, Egito, Armênia e Argélia (ALVARADO et al., 2004). Também há relatos da ocorrência da espécie em outras regiões do mundo, como Austrália, Argentina, Uruguai e Chile (ALVARADO et al., 2004). No Brasil, o ácaro foi interceptado em barreiras fitossanitárias em mudas vindas de Portugal (REIS et al., 2005), porém, em maio de 2010, a espécie foi detectada pela primeira vez em mudas de oliveira no viveiro localizado na Estação

\footnotetext{
IDepartamento de Fitossanidade, Faculdade de Agronomia “Eliseu Maciel” (FAEM), Universidade Federal de Pelotas (UFPel), Campus Universitário s/n, CP 354, Pelotas, RS, Brasil. E-mail: mbage@bol.com.br. *Autor para correspondência.

IIEmbrapa Clima Temperado (EMBRAPA/CPACT), Pelotas , RS, Brasil.
} 
Experimental Maria da Fé, em Minas Gerais (AGROSOFT BRASIL, 2010; REIS et al., 2011).

Em monitoramentos realizados em olivais no

Rio Grande do Sul, foi constatada a presença do ácaro nos municípios de Pelotas (S 3140’54” W 52²6’11”), Candiota (S $\left.31^{\circ} 23^{\prime} 40^{\prime \prime} \mathrm{W} 53^{\circ} 45^{\prime} 22^{\prime \prime}\right)$, Bagé (S $31^{\circ} 08^{\prime} 44^{\prime \prime}$

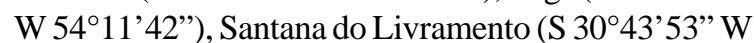

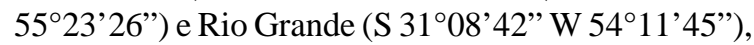
nos meses de novembro de 2010 a fevereiro de 2011. A espécie foi identificada pela $\mathrm{Dr}^{\mathrm{a}}$ Denise Navia da Embrapa Recursos Genéticos e Biotecnologia de Brasília, DF. Os ácaros foram encontrados em folhas novas de plantas jovens (três a seis anos) e com até 40 anos de idade das cultivares 'Arbequina', 'Arbosana', 'Manzanilla', ‘Galega', 'Cordovil de Sêrpa', 'Koroneiki', 'Grapollo' e 'Picual'. Nos pomares infestados, foram encontradas populações superiores a 20 ácaros por folha, sem constatar a presença da espécie em frutos, nos quais pode causar deformações.

O único hospedeiro conhecido é a oliveira (Olea europaea L.). Estudos realizados na Universidade da Califórnia (1994) demonstraram que a cultivar 'Ascolano’ é a mais suscetível, seguida por ‘Sevillano', 'Manzanilla' e 'Mission'. Na Austrália, a espécie é encontrada em diversas cultivares, incluindo 'Paragon' e 'Barnea' (KNIHINICKI, 2010).

$\mathrm{O}$ ácaro possui formato vermiforme, achatado, com anéis medindo de 0,1 a $0,35 \mathrm{~mm}$ de comprimento. Na parte frontal do corpo, a espécie tem apenas dois pares de pernas, apresentando cor âmbar, branco e laranja (Figura 1) (GONZÁLES et al., 2000, SPOONER-HART et al., 2007).
As fêmeas de inverno são encontradas na parte superior das folhas em número de três a quatro. Com o início da primavera, as fêmeas deslocam-se para as gemas e folhas novas, onde começam a se reproduzir. Até o momento, não foram conduzidos trabalhos sobre a biologia deste ácaro (SPOONER-HART et al., 2007).

A atividade mais intensa das formas jovens e adultas ocorre na primavera e outono, quando provocam maiores danos devido à suç̧ão da seiva causando enrolamento de folhas, diminuição da fotossíntese, queda de folhas e repolhamento, devido à superbrotação da planta. Esses períodos coincidem com o crescimento máximo da oliveira e com a presença de muitos brotos, que são os preferidos pelo ácaro devido à maciez dos tecidos. Os focos estão distribuídos por toda a planta onde ocorrem os brotos. As colônias são formadas neste período, infestando a parte superior das folhas e, quando a população é alta, também atacam a parte inferior das folhas jovens e brotos (KNIHINICKI, 2010).

A floração é um momento crucial para os danos, porque, nessa época, as colônias atacam as flores, o que resulta em frutos deformados. Em junho a população cai drasticamente, para aumentar novamente na primavera seguinte. As temperaturas extremas causam declínios nos níveis de infestação (ALVARADO et al., 2004; NEVADO et al., 2006). O ácaro provoca distorção das folhas e abortamento de gemas em mudas e árvores jovens, resultando em retardo do crescimento e deformação da planta. Já em árvores em produção, causa deformação nas folhas e frutos (Figura 2), ocorrendo protuberâncias e depressões na superfície de forma

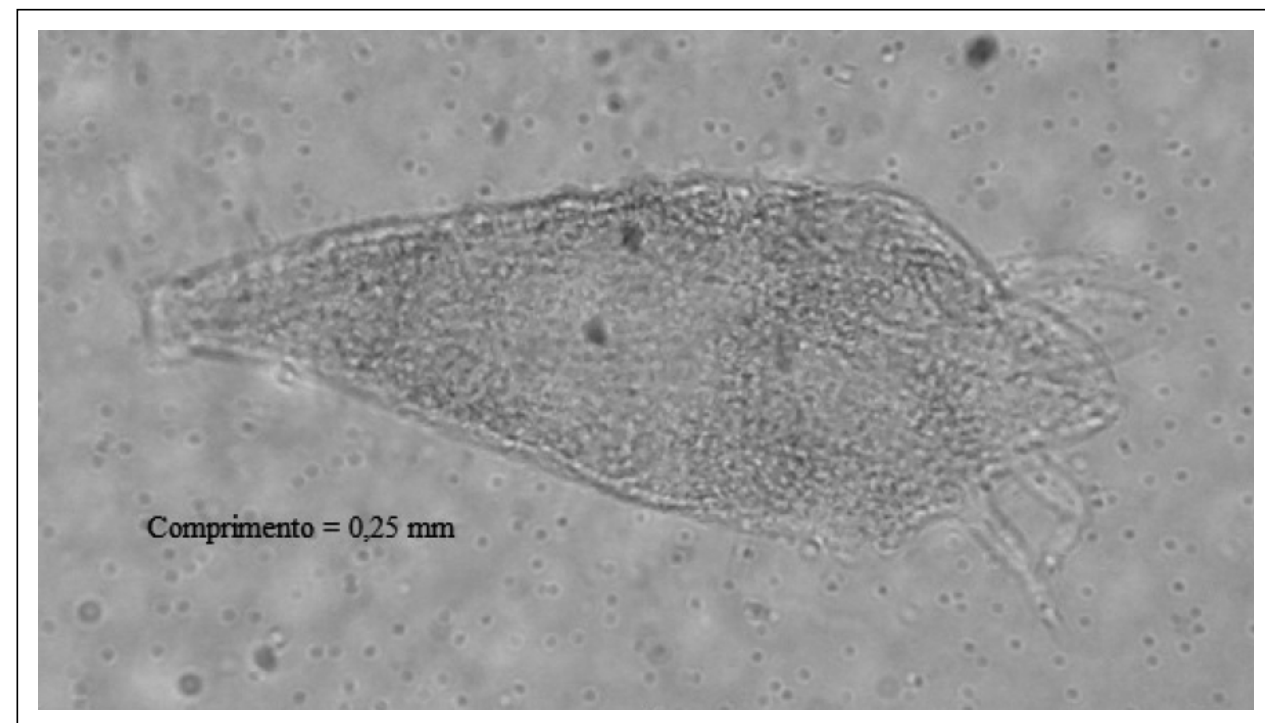

Figura 1 - Oxycenus maxwelli.(Keifer, 1939) (foto microscópio com aumento de 100x) (foto: Ricalde, M.P.). 


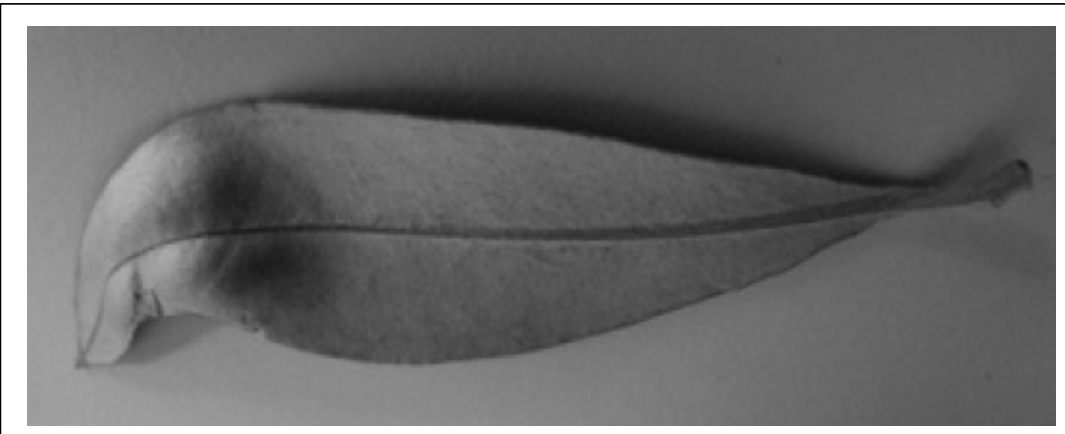

Figura 2 - Deformações nas folhas, causadas por Oxycenus maxwelli (foto: Ricalde, M.P.).

variável, que devem ser consideradas apenas se o fruto destina-se à mesa (SPOONER-HART et al., 2007).

Este é o primeiro registro da espécie $\boldsymbol{O}$. maxwelli atacando a oliveira no Estado do Rio Grande do Sul.

\section{AGRADECIMENTOS}

Ao Conselho Nacional de Desenvolvimento Científico e Tecnológico (CNPq), pela Bolsa de Doutorado do autor M. P. Ricalde, à Universidade Federal de Pelotas (UFPel), pelos ensinamentos no Doutorado e pela cedência dos laboratórios para a pesquisa, à Embrapa, pelo apoio na execução do trabalho e a Dr ${ }^{\mathrm{a}}$ Denise Navia da Embrapa Recursos Genéticos e Biotecnologia de Brasília, DF, pela identificação do ácaro.

\section{REFERÊNCIAS}

AGROSOFT BRASIL. EPAMIG notifica ocorrência de praga exótica em oliveiras. AGROSOFT, 17 jun. 2010. Online. Disponível em: <http://agrosoft.com/pdf.php/?node=214633>. Acesso em: 15 fev. 2011.

ALVARADO, M. et al. La acariosis del olivar, uma plaga em expansión estos últimos años. Sevilla: Laboratorio de Sanidad Vegetal, Consejeria de Agricultura y Pesca, 2004. p. 38-40 (Dossier Olivar). Disponível em: <http://www.marm.es/ ministerio/pags/biblioteca/revistas/pdf_vrural/ Vrural_2004_188_38_40.pdf>, Acesso em: 10 jan. 2011.

COUTINHO, E.F. et al. Cultivo de oliveira (Olea europaea L.). Pelotas: Embrapa Clima Temperado, 2009. 125p. (Sistema de Produção, 16). Disponível em: <http://www.cpact.embrapa.br/ publicacoes/download/sistemas/sistema_16.pdf>, Acesso em: 20 jan. 2011.

GONZÁLES, M.I. et al. Los eriófidos (Acarina, Eryophidae) del olivar de la província de Sevilla. Problemática y control. Boletin Sanidad Vegetal Plagas, n.26, p.203-214, 2000 Disponível em: <http://www.marm.es/ministerio/pags/biblioteca/ revistas/pdf_plagas\%2FBSVP-26-02-203-214.pdf $>$, Acesso em: 23 fev. 2011.
NEVADO, M.I.C. et al. Acariosis o sarna del olivo. Extremadura/ES: Grupo de Trabajo de Laboratorios de Diagnóstico, 2006. 2p. 2006. (Ficha 281). Disponível em: <http://www.marm.es/ministerio/pags/exposiciones/aceite/www/ imagenes/pdf/fd_281.pdf >, Acesso em: 23 fev. 2011.

REIS, M.T. dos et al. Interceptação do ácaro Oxycenus maxwelli (Keifer) (Prostigmata: Eriophyidae) em mudas de Oliveira (Olea europea L.). In: ENCONTRO DO TALENTO ESTUDANTIL DA EMBRAPA RECURSOS GENÉTICOS E BIOTECNOLOGIA, 10., 2005, Brasília, DF. Anais: resumos dos trabalhos. Brasília: Embrapa Recursos Genéticos e Biotecnologia, 2005. 203p. Disponível em: <http:// www.alice.cnptia.embrapa.br/handle/doc/187651>, Acesso em: 23 fev. 2011.

REIS, P.R. et al. First record of the olive bud mite Oxycenus maxwelli (Keifer) (Acari: Eriophyidae) from Brazil. Neotropical Entomology, v.40, n.5, p.622-624, 2011. Disponível em: <http://dx.doi.org/10.1590/S1519566X2011000500017>, Acesso em: 10 nov 2011. doi: 10.1590/ S1519-566X2011000500017.

SPOONER-HART, R. et al. Field guide to olive pests, diseases and disorders in Australia. Australia: RIRDC, 2007. 68p. Disponivel em: <http://www.google.com.br/ url?sa=t\&rct=j\&q=olive\%20bud\%20mite\%20\%E2\%80\%93\%2 0oxycenus\%20maxwelli\&source=web\&cd=4\&ved=0CEIQFjAD\&url=h ttps\%3A\%2F\%2Frirdc.infoservices.com.au\%2Fdownloads\%2F07153\&ei=KIsqT8HmFqS42QXekMH3Dg\&usg=AFQjCNEB8j2qN 8PCLnOklv20BLFSSOdaoA\&cad=rja>, Acesso em: 15 fev. 2011.

KEIFER, H.H. Eriophyid Studies III. Bulletin of the Californian Department of Agriculture, n.28, p.144-162, 1939. Disponível em: <http://www.cdfa.ca.gov/plant/ppd/PDF/ Bulletin1939_EriophyidStudiesIII.pdf $>$, Acesso em: 15 fev. 2011.

KNIHINICKI, D. Olive bud mite - Oxycenus maxwelli. Australia: Agricultural Scientific Collections Unit, 2010. 2p. Disponível em: <http://www.dpi.nsw.gov.au/_data/assets/ pdf_file/0005/353624/Olive-bud-mite-Oxycenus-maxwelli.pdf>, Acesso em: 12 jan. 2011. 